\title{
A RELAÇÃO HUMANO-CÃO NO CONTEXTO DA SAÚdE HUMANA: CONSIDERAÇÕES SOBRE CONTEÚDOS VEICULADOS NO INSTAGRAM
}

\section{ARTIGO ORIGINAL}

PALLOTTA, Mara Lucia ${ }^{1}$

CUNHA, Maria Claudia ${ }^{2}$

PALLOTTA, Mara Lucia. CUNHA, Maria Claudia. A relação humano-cão no contexto da saúde humana: considerações sobre conteúdos veiculados no Instagram. Revista Científica Multidisciplinar Núcleo do Conhecimento. Ano 05, Ed. 08, Vol. 04, pp. 151-172. Agosto de 2020. ISSN: 2448-0959, Link de acesso: https://www.nucleodoconhecimento.com.br/saude/relacao-humano-cao

\section{RESUMO}

Introdução: O cão está presente na vida do ser humano desde os primórdios da civilização e vem ocupando gradativamente novos papéis na sociedade. Por conta da ajuda mútua que caracteriza o vínculo entre essas duas espécies, atualmente o cão, comprovadamente reconhecido como ser senciente, se estabelece como membro das chamadas famílias multi-espécie e, mais que isso, a efetividade de sua presença no apoio à pessoas com vulnerabilidade física, psíquica e/ou social - a chamada Intervenção Assistida por Animais (IAA), vem sendo abordada cientificamente bem como, de forma ampla, divulgada nas redes sociais digitais. Objetivo: Pesquisar a relação humano-cão no contexto da saúde humana em postagens feitas na rede social Instagram. Método: Pesquisa exploratório-descritiva de recorte transversal na qual

\footnotetext{
1 Bacharel em Comunicação Social pela Fundação Armando Álvares Penteado (FAAP).

2 Professora Titular do Departamento de Clínica Fonoaudiológica da Faculdade de Ciências Humanas e da Saúde da PUC - SP.
} 
foram coletadas postagens feitas no Instagram, buscadas por meio de hashtags previamente selecionadas - \#terapiaassistidaporanimais e \#animalassistedtherapy - termos escolhidos por serem indexados como Descritores de Ciências da Saúde - DeCS. Foram coletadas postagens durante 10 minutos diários para cada uma dessas hashtags de segunda a domingo, em horários definidos por sorteio, em um período de três meses do ano de 2019 (Julho, Agosto e Setembro). Resultados: Os resultados foram descritos a partir das seguintes categorias de postagens: de acordo com a localização geográfica de origem; quanto às características dos assistidos (tipo de fragilidade, sexo e faixa etária), quanto ao local de atendimento; quanto ao tipo de atividade realizada; quanto às áreas de conhecimento envolvidas. Assim, foi possível a compreensão do fenômeno estudado a partir de análises quantitativas e qualitativas dos resultados. Conclusão: Esta pesquisa ofereceu dados significativos sobre essa relação inter espécie no contexto da saúde humana, uma vez que a rede social possibilitou acesso ao cenário mundial contemporâneo na abordagem do tema.

Palavras-chave: Terapia Assistida por Animais, cães, rede social.

\section{INTRODUÇÃO}

O meio digital é um ecossistema virtual que concentra mais da metade da população mundial com cerca de 4 bilhões de pessoas conectadas (ITU - International Telecommunication - ONU, 2018).

Visto que o cotidiano da sociedade é diretamente moldado pela mídia e esta participa ativamente na construção do mundo social (THOMPSON, 2011), há hoje um meio com alcance ainda maior que as mídias tradicionais por conta da Internet, cuja consequência é uma sociedade altamente impactada por conteúdos que geram novas tendências dia após dia. A telefonia celular tornou a internet ainda mais acessível onde temos que sete a cada dez brasileiros estão conectados à rede (CGI.BR, 2018).

Pesquisa feita pelas empresas HootSuite ${ }^{1}$ e We Are SociaR (2019) mostra que cada brasileiro usa 3 horas e 34 minutos de seu dia em atividades nos meios digitais, especificamente nas redes sociais. 
Conforme Marteleto (2001), as redes sociais abrigam um conjunto de participantes autônomos, unindo ideias e recursos em torno de valores e interesses compartilhados. É por meio desse universo de mídias digitais em geral que somos atingidos diariamente por informações (só no Instagram são publicados uma média 100 milhões de posts diários, em todo o mundo, segundo Statista - The Statics Portal, um portal provedor líder de dados de mercado e consumidor).

Nesse contexto, o presente estudo parte da observação de que significativa parcela dos conteúdos veiculados nas redes sociais testemunha a interação do ser humano com animais de estimação, uma vez que a relação inter espécie vem se aprimorando, onde o cão ocupa hoje maior espaço e funções junto da nova configuração social familiar denominada multiespécie - a família que reconhece os animais de estimação como membros (FARACO, 2008). Chama a atenção a significativa quantidade de hashtags que compreendem conteúdo com imagens de cães prestando assistência à pacientes hospitalizados ou apoiando pessoas com indicadores de fragilidade em ambientes domésticos ou instituições. E, considerando-se que as redes sociais exercem forte influência, tanto na difusão de inovações quanto na veiculação da informação e do conhecimento (TOMAÉL; ALCARÁ; DI CHIARA, 2005), parece oportuno o presente estudo.

\section{OBJETIVO}

Pesquisar a relação humano-cão no contexto da saúde humana em postagens na rede social Instagram.

\section{REVISÃO BIBLIOGRÁFICA}

\subsection{O AMBIENTE DIGITAL}

Uma vez que o campo de pesquisa é um ambiente essencialmente digital, a compreensão desse meio visa a contribuir com este estudo. É fato que a sociedade se transformou a partir da criação da Internet e, mais ainda, sob o impacto das inovações da Web 2.0. Segundo Ferreira (2007, p. 245) "a Web 2.0 é feita para e pelos 
utilizadores. Estes deixaram o patamar da observação e passaram a dar o seu contributo e marca pessoal num espaço que é cada vez mais de todos".

A Web 2.0 é ambiente onde as personas - termo criado por Tavares (2010, p. 2) poderiam tanto gerar como consumir informações além de debater suas ideias de forma democrática. Vale apontar que nela foram criados os vínculos sociais por meio das redes, cujo ambiente é o cenário deste estudo.

\subsection{O INSTAGRAM E SUA CARACTERIZAÇÃO}

O Instagram é um aplicativo mobile gratuito com o perfil de rede social cuja função é o compartilhamento de fotos e vídeos entre os usuários, que podem comentar e curtir as postagens (entre outras funções no aplicativo que tem sido implementadas).

Basicamente esse aplicativo possibilita que o usuário proprietário de uma conta capture imagens em fotografia ou vídeo, aplique filtros nessas imagens e as publique em seu perfil, sendo que esse conteúdo pode ser visualizado por outros usuários do aplicativo. Sobre encontrar conteúdos que sejam o foco de interesse dos usuários, o recurso utilizado são as hashtags (representadas pelo caracter cerquilha \#), que visam agrupar conteúdos para facilitar os usuários das redes sociais a encontrá-los. De acordo com Pinto, Theodoro e Oliveira (2016, pg. 35), "hashtags são palavras ou expressões com a função de categorizar postagens em mídias sociais, que tornam o conteúdo apto para a busca. São de livre criação, portanto não há regras ou restrições para criá-las".

Conforme pesquisa elaborada sobre interesses dos frequentadores dessa rede, $49 \%$ dos usuários seguem perfis que tratam sobre Saúde, incluindo-se perfis de temas relacionandos à Saúde Humana (D’ANGELO, 2019). É nesse nicho que está o universo desta pesquisa. 


\subsection{INTERAÇÃO ENTRE HUMANOS E CÃES: O PROCESSO HISTÓRICO DA DOMESTICAÇÃO CANINA}

Não existem dados precisos sobre a aproximação entre o ser humano e o cão. Conforme Fogle (2006), o ancestral do cão viveu há 7 milhões de anos. Demais estudos afirmam que a domesticação do cão teve início no período neolítico, com o sedentarismo das sociedades, que deixaram de ser nômades fixando-se em regiões, passando a se dedicar ao cultivo (GALIBERT et al., 2011).

Lobos se aproximaram das tribos em busca de sobras de alimentos, oferecendo proteção ao território e ajuda na caça e, com isso, essa interação aconteceu por meio de um benefício mútuo (LANTZMAN, 2013).

A partir do momento em que o cão teve permissão para entrar na moradia da família, deixou de ser alimento e ganhou um nome, ele passa a ser um animal de estimação e isso o distingue dos demais e, seja qual for seu atributo, o principal deles é uma lealdade afetuosa em relação à espécie humana (THOMAS, 2001).

Nesse contexto, é compreendido que o cão tenha desenvolvido habilidades para relacionar-se com o ser humano (LIMA; SOUZA, 2004; DOMINGUES, 2007; ALBUQUERQUE; CIARI, 2016), criando vínculos sociais, uma característica inata de ambas as espécies como uma estratégia para adaptação e sobrevivência (BOWLBY, 1990), sendo o vínculo uma necessidade tão primária quanto satisfazer fome ou sede (GOMES; MELCHIORI, 2011). De acordo com o Comportamento do Apego ${ }^{3}$ (BOWLBY, 1990), é oportuno um olhar sobre essa relação de forma análoga ao que ocorre entre crianças e seus cuidadores (FARACO, 2008).

Amparadas pelas evidências científicas, as aptidões do cão vem se mostrando apropriadas como coadjuvantes em processos terapêuticos e ganham o poder de influenciar a sociedade, uma vez que agora são divulgadas em redes sociais digitais. 


\subsection{OS CÃES NO CONTEXTO DA SAÚDE HUMANA}

Porto e Cassol (2007) sustentam que a união entre humanos e cães sempre teve como veículo principal o mútuo afeto, o que causa um estado de relaxamento e espontaneidade.

Revisitando a história da presença do cão nesse contexto, depara-se com os primeiros registros, feitos em 1792, que mostram animais na interação com humanos em pacientes com a saúde mental comprometida, no Retiro York, Inglaterra (SERPELL, 1996; FINE, 2000).

Florence Nightingale (1860, p. 103) postula que um animal de estimação poderia ser uma excelente companhia para pessoas com casos de doenças crônicas. Na mesma época (1867), na Alemanha, Bethel Institute desenvolve atividades com a inclusão de animais em pacientes epilépticos (GRANDGEORGE; HAUSBERGER, 2011).

Enquanto isso Freud, que também tinha uma relação próxima com seus cães, já adotava a presença de sua cadela da raça Chow Chow - Jofi - no setting das sessões de psicanálise (RUITENBEEK, 1973).

Veteranos das Guerras Mundiais que tiveram a saúde mental comprometida puderam contar com a companhia de animais quando a monotonia dos ambientes hospitalares era quebrada mediante essa interação (CHANDLER, 2005).

$\mathrm{Na}$ década de 60 surgem, por meio do psiquiatra infantil norte-americano Boris Levinson, os primeiros relatos científicos sobre a relação paciente-animal no setting, sendo o início do reconhecimento da Terapia Assistida por Animais (TAA) como um meio terapêutico na área da saúde (HOOKER; FREEMAN; STEWART, 2002).

Nise da Silveira foi pioneira na utilização da Terapia Assistida por Animais - TAA no Brasil em pacientes psicóticos internados (DOMINGUES, 2007). Hannelore Fucks, médica veterinária e psicóloga (MACHADO; ROCHA; SANTOS, 2008), corroborou com a presença de animais em visitas a internados em instituições na década de 80 . 
Em 1996, a organização americana Delta Society - The Human-Animal Health Connection define nomenclaturas para atividades que envolvem animais e as contextualiza, o que é complementado em 2014 pela International Association of Human-Animal Interactions Organizations (IAHAIO $)^{4}$, que criou definições e diretrizes para todo o trabalho de intervenções que viessem a envolver cães em serviço com humanos.

Nessa direção, a produção científica vem confirmando que a presença de animais em geral, especificamente os cães, exerce um papel coadjuvante em terapias nas mais diversas necessidades do ser humano.

Domingues (2007) relatou o caso do paciente Pedro e da cadela Pequena, quando a TAA possibilitou uma diminuição do comportamento retraído e agressivo do paciente, obtendo um ganho significativo na terapia fonoaudiológica do sujeito.

De acordo com Ichitani (2015), em pesquisa feita para analisar a sensação de dor em crianças hospitalizadas, ficou evidente que a AAA se mostrou eficiente quanto à sensação de dor reduzida referida pelos sujeitos estudados.

No que tange à Educação Assistida por Animais (EAA), há Petenucci (2018) relatando em sua pesquisa que a leitura se torna uma experiência positiva e agradável quando na presença de um cão.

\subsection{OS CÃES NO CONTEXTO DAS REDES SOCIAIS}

As redes sociais são ambientes em que as pessoas se unem por gostos, valores e necessidades similares. O Instagram, como uma rede social criada exclusivamente para compartilhamento de imagens acrescidas de uma legenda sintética, transformouse num vasto catálogo de pessoas, negócios, ideologias - cada usuário cria uma persona que é o traje com que se veste e por meio do qual quer ser reconhecido pelos contatos com os quais quer interagir (COELHO, 2016):

A maneira de usar o Instagram, portanto, da mesma forma que outras redes sociais, fica a critério dos usuários, que escolhem as fotos que irão 
postar, a maneira como irão se comunicar com outros usuários através dos comentários, e a postura que irão adotar em seu perfil e nas narrativas construídas nele (COELHO, 2016, p. 54).

Na rede social Instagram encontram-se os instagramers - proprietários de perfis que também influenciam suas comunidades de seguidores por meio de seu conteúdo e que, atualmente podem ser inclusive representados por cães - fenômeno esse que ocorre por conta de um novo contorno na sociedade familiar que, de acordo com Seguin, Araújo e Cordeiro (2016), estreitou o relacionamento entre humanos e cães, sendo que eles passam a ser considerados como parte integrante da família, deixando de ser um objeto de estimação para ser um sujeito de direitos e, inclusive, a ganhar reconhecimento nas plataformas de mídias sociais (KÉRTÉSZ; BERZLEJA, 2019).

Segundo Salles, a quantidade de postagens marcadas pela hashtag \#dogsofinstagram no início de 2020 chegaram a um total de 131 milhões. Segundo (CRAMER, 2018, p. 9), o uso de animais - especificamente cães - nas redes sociais, resume-se num fator muito prático: "eles não compartilham de opiniões políticas ou qualquer assunto controverso". E ainda oferecem uma sensação tranquila e amena ao conteúdo de um feed ${ }^{5}$; mesma sensação de que a presença física de um cão nos oferece (KÉRTÉSZ; BERZLEJA, 2019).

Nessa perspectiva, sugere-se que a presença dos cães nos afeta positivamente e permanecem contíguos a nós desde o início da sua domesticação, desempenhando papéis propostos por delineamentos sociais contemporâneos.

\section{MÉTODO}

O presente estudo baseia-se numa pesquisa exploratório-descritiva. As variáveis não foram estabelecidas a priori sendo que, após a observação do material coletado os dados foram descritos, reconhecidos e analisados de forma quantitativa bem como qualitativamente. 
Os participantes cujas imagens foram analisadas foram isentos do Termo de Consentimento Livre e Esclarecido, uma vez que essas imagens foram publicadas numa rede social em meio digital.

Este projeto foi aprovado pelo Comitê de Ética da PUC-SP sob o CAAE 23703119.0.0000.5482, em 27/11/2019.

\subsection{CASUÍSTICA}

Conteúdos publicados na rede social Instagram - n=155 —, sob duas 02 Hashtags \#terapiaassistidaporaniamais e \#animalassistedtherapy, ambos os termos escolhidos por serem indexados nos Descritores de Ciências da Saúde (DeCS), que foi pesquisado durante um período determinado.

Critérios de inclusão: fotos e vídeos que demonstram a interação entre humanos e cães no contexto da saúde humana, sejam elas institucionais ou realizadas de forma doméstica.

Critérios de exclusão: conteúdos com fins publicitários; perfil de imagens posadas ${ }^{19}$ que não demonstrem uma atividade entre ser humano e cão; perfil de imagens que contenham apenas o humano sem o cão; imagens que contenham apenas o cão sem o humano; selfies 6 . 


\subsection{DELINEAMENTO DO ESTUDO}

Fluxograma 1 - Delineamento do Estudo

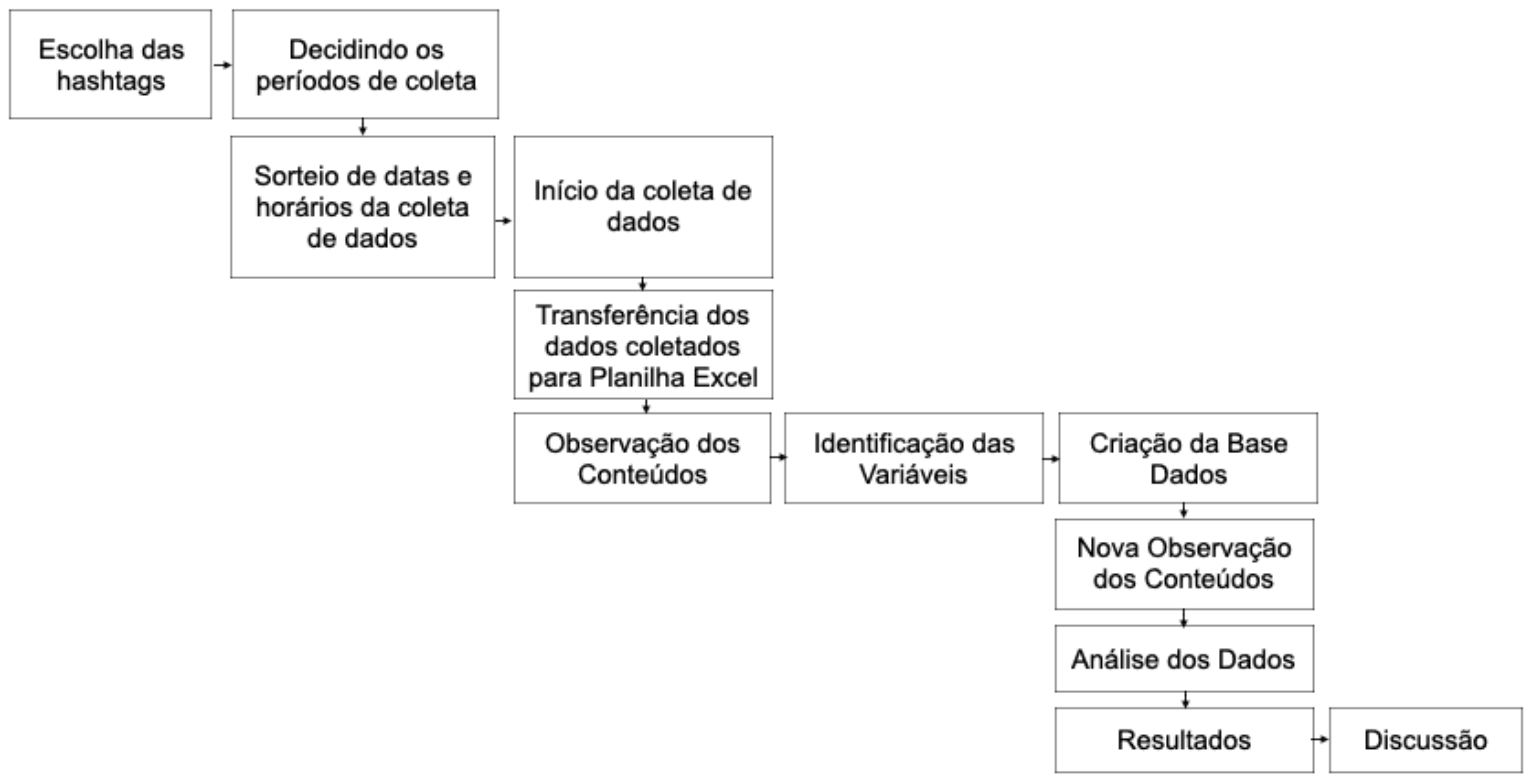

\subsubsection{DEFININDO TERMOS DE PESQUISA}

A fim de determinar as hashtags que seriam pesquisadas, foram atribuídos os critérios: pertinência com o estudo; indexação nos Descritores de Ciências da Saúde (DeCS); grupos de conteúdo relacionados a cada hashtag que contenham a partir de 1.000 postagens para que se entenda como conteúdo relevante. Foram encontrados no DeCS com hashtags correnspondentes os termos: Terapia Assistida por Animais e suas versões nos idiomas Inglês e Espanhol: Animal Assisted Therapy e Terapia Asistida por Animales. Foi desconsiderada a hashtag na versão em Espanhol \#terapiaassistidaporanimales - por conter quantidade menor que 1.000 postagens.

\subsubsection{DEFININDO DATAS PARA A COLETA DE DADOS}

A coleta de dados relativos às postagens foi feita durante 20 (vinte) minutos por dia, 10 (dez) minutos para cada hashtag, de segunda a domingo, em horários previamente determinados conforme sorteio que definiu datas, dias da semana e os respectivos 
horários da coleta para cada dia. Os meses foram decididos de forma aleatória, levando em consideração o cronograma para a conclusão do projeto, a saber: Junho, Agosto e Setembro do ano de 2019. Foram feitos sorteios para definir as datas de cada mês bem como os horários de coleta por dia.

Quadro 1 - Cronograma Final de Coleta de Dados

\begin{tabular}{|l|l|l|l|}
\hline Dia do Mês & Dia da Semana & Mês & $\begin{array}{l}\text { Horário de Início da } \\
\text { Coleta }\end{array}$ \\
\hline $\mathbf{6}$ & quinta-feira & Junho & $23 \mathrm{~h}$ \\
\hline $\mathbf{1 1}$ & terça-feira & Junho & $7 \mathrm{~h}$ \\
\hline $\mathbf{1 4}$ & quarta-feira & Agosto & $14 \mathrm{~h}$ \\
\hline $\mathbf{1 6}$ & sexta-feira & Agosto & $16 \mathrm{~h}$ \\
\hline $\mathbf{2 2}$ & domingo & Setembro & $13 \mathrm{~h}$ \\
\hline $\mathbf{2 3}$ & segunda-feira & Setembro & $5 \mathrm{~h}$ \\
\hline $\mathbf{2 8}$ & sábado & Setembro & $14 \mathrm{~h}$ \\
\hline
\end{tabular}

\subsection{PROCEDIMENTO}

Como instrumento para coleta de dados, foi utilizado um aparelho celular com Sistema Operacional IOS - especificamente Iphone 7. Cada publicação verificada teve sua URL (Uniform Resource Locator) salva, utilizando a função "Favoritos" do próprio aplicativo e transferidas para uma planilha no software Microsoft Excel. Os conteúdos que se mostraram fora dos critérios estabelecidos foram transferidos para outra planilha. Os dados que representaram a amostra foram abertos no navegador para visualização, de acordo com seguintes etapas: 1 . Observação do proprietário do perfil; 2. No caso de o proprietário do perfil não ser uma instituição e sim um animal ou um ser humano, a investigação parte em busca do nome da instituição responsável pela publicação e informações sobre o tipo de trabalho desenvolvido; 3. Observação de recursos inerentes ao aplicativo como: marcações de pessoas na imagem, localização, leitura da bio no perfil, leitura das legendas e visita ao website esclarecendo demais demandas para o estudo. Dessa forma conclui-se a seguinte base de dados: 
Quadro 2 - Caracterização final das variáveis para coleta de dados

SOBRE A INSTITUIÇÃO

\begin{tabular}{|l|l|l|l|l|l|}
\hline Url & $\begin{array}{l}\text { Proprietário do } \\
\text { perfil }\end{array}$ & $\begin{array}{l}\text { Instituição } \\
\text { responsável }\end{array}$ & Cidade Estado País & & \\
\hline
\end{tabular}

SOBRE OS ASSISTIDOS
Sexo
Faixa Etária
Fragilidade

SOBRE O ATENDIMENTO

\begin{tabular}{l|l|l} 
Local de Atendimento Área Profissional & Tipo de Atividade
\end{tabular}

\subsection{CRITÉRIOS DE ANÁLISE DOS RESULTADOS}

Foi realizada a análise estatística por meio de frequências absolutas (n) e relativas (\%). Foram verificadas outras fontes de pesquisa, como o site institucional e a rede social Facebook da Instituição a fim de explorar de forma qualitativa o perfil de atendimento de cada um dos serviços encontrados.

\section{RESULTADOS}

Foram coletadas 464 postagens, das quais foram excluídas 349 por não fazerem parte dos critérios de seleção. Assim, foram avaliadas 115 imagens entre fotos e vídeos: $54,8 \%$ publicadas sob a hashtag \#terapiaassistidaporanimais (postagens nacionais) e 45,2\% sob a hashtag \#animalassistedtherapy (postagens internacionais). Os resultados foram descritos a partir das variáveis: postagens de acordo com a localização geográfica de origem; quanto às características dos assistidos: tipo de fragilidade, sexo e faixa etária; postagens quanto ao local de atendimento; quanto ao tipo de atividade realizada e quanto área de conhecimento envolvida.

\subsection{POSTAGENS DE ACORDO COM A LOCALIZAÇÃO GEOGRÁFICA DE ORIGEM}

A maior quantidade de postagens foi feita pelo Brasil (57\%). Demais postagens ocorreram dentro de um padrão nos demais locais, exceto EUA (21\%) que se 
destacou dos países da Europa e Oceania (12\%) e América (6\%). Nas postagens nacionais, o Estado da Paraíba aparece com o maior número de postagens $(22 \%)$, seguido por perfis dos Estados do Sudeste: Minas Gerais (19\%); Rio de Janeiro (16\%) e São Paulo (12\%), respectivamente.

\subsection{CARACTERÍSTICAS DOS ASSISTIDOS: FRAGILIDADE, SEXO E FAIXA ETÁRIA}

O trabalho com pessoas hospitalizadas é o mais frequente nas postagens $(47 \%$ nas nacionais e $29 \%$ nas internacionais), seguido de postagens de pacientes com necessidades especiais: Transtorno do Espectro Autista, Síndrome de Down e Paralisia Cerebral, com praticamente a mesma quantidade de postagens independente do local de origem (33\% nacionais e $29 \%$ internacionais). Estudantes não foram observados nas postagens nacionais. As postagens internacionais mostram um número significativo dessa categoria (19,4\%). A categoria Internados englobou idosos que vivem em instituições de acolhimento (12,5\% nacionais e 9,7\% internacionais.

Quanto à faixa etária, crianças e idosos são os assistidos que mais aparecem nas postagens nacionais $(39,3 \%$ e $34,4 \%$ respectivamente). Nas postagens internacionais, assistidos de 10 a 18 anos são os mais frequentes (22\%) e os idosos surgem em poucas ocorrências se comparado às postagens nacionais (15,9\%).

Sobre o sexo dos assistidos, o sexo masculino aparece na maior parte das postagens (38,1\% em postagens nacionais e $64,3 \%$ em internacionais). Imagens que mostram grupos de pacientes de ambos os sexos equivalem a $22,2 \%$ nas postagens nacionais e $14,3 \%$ nas internacionais. Em 3,2\% das imagens nacionais não foi possível identificar o sexo.

Observou-se também que, dentre os tipos de fragilidades mais evidentes, o sexo masculino prevalece nos Pacientes com Necessidades Especiais praticamente se equivalem nos pacientes Hospitalizados, como pode-se observar no gráfico abaixo: 
Gráfico 1 - Sexo dos Assistidos x Tipo de Fragilidade

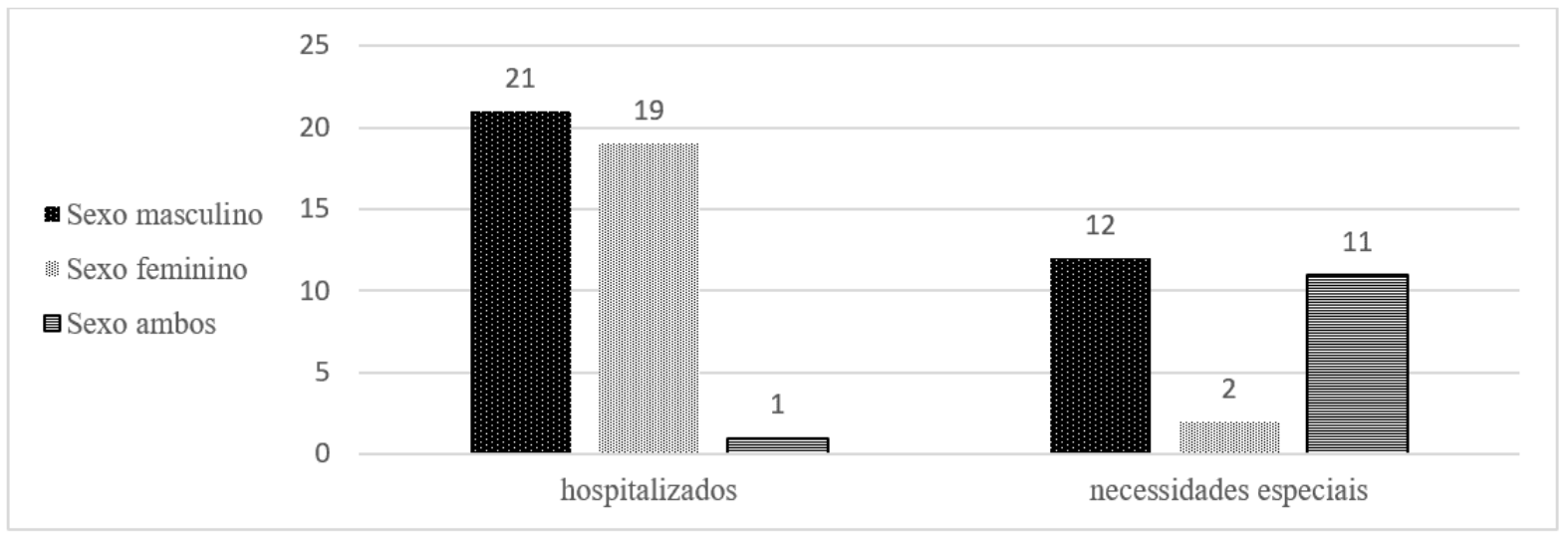

\subsection{LOCAIS DE ATENDIMENTO}

Os hospitais são os que contém maior número de postagens nas cenas de serviços de Intervenções Assistidas por Animais (IAA), tanto nacional como internacionalmente com $92,4 \%$ das postagens. Instituições de apoio a pessoas com necessidades especiais é a segunda ocorrência nas postagens nacionais (24,0\%). Nas postagens internacionais, escolas, parques e domicílios são locais que surgem com frequência considerável, (32,4\%) o que já não ocorre nas postagens nacionais. (2,0\%).

\subsection{TIPO DE ATIVIDADES REALIZADAS}

O Contato ${ }^{7}$ entre o humano e cão (74\% tanto nacionais quanto internacionais) foi a atividade mais evidenciada. Atividades como brincar (10\%), ler com o cão (8\%), escovar o cão (4\%) ocuparam a maior parte nas postagens internacionais e foram irrelevantes nas postagens nacionais. A Leitura com o cão aparece em $2 \%$ das postagens nacionais e $8 \%$ nas internacionais, todas nos EUA.

\section{5 ÁREA PROFISSIONAL ENVOLVIDA}

As postagens nacionais mostraram em sua maior parte serviços envolvendo a área de Fisioterapia (14\%) e Psicologia (13\%). Contudo, em muitas delas não foi possível identificar qual a área do conhecimento dos profissionais envolvidos nos respectivos projetos $(67 \%)$ e a Interdisciplinaridade nos serviços observados foi inexistente. Em 
contrapartida, as postagens internacionais demonstraram projetos adequados ao perfil Interdisciplinar (47\%), em sua maior parte seguido pela área da Psicologia (12\%), Serviço Social (4\%), Terapia Ocupacional (2\%) e Medicina Humana (2\%).

\section{DISCUSSÃO}

A exploração deste universo ofereceu acesso a conteúdos na rede social Instagram que demonstraram significativa presença de cães como influenciadores e proprietários de perfis (KÉRTÉSZ; BERZLEJA, 2019), confirmando o animal como membro da família multiespécie (FARACO, 2008).

Sobre o critério de termos de busca, em razão de as hashtags serem termos de livre criação (PINTO; THEODORO; OLIVEIRA, 2016), um conjunto considerável de hashtags não puderam ser contempladas, já que não obedeciam aos critérios de seleção propostos no método.

Não foram verificadas nas legendas das imagens as modalidades das Intervenções Assistidas por Animais (IAA), como Atividades Assistidas por Animais, Terapia Assistida por Animais e Educação Assistida por Animais, AAA, TAA e EAA, respectivamente. A subjetividade das imagens, bem como informações textuais muitas vezes precárias não tornaram evidentes essas diferentes abordagens.

Quanto à localização geográfica de origem, pode-se depreender que a grande quantidade de postagens sobre Intervenções Assistidas por Animais (IAA) nos EUA à prática desse modelo terapêutico no país com investigações científicas desde a década de 60 (LEVINSON, 1969).

As imagens de pacientes hospitalizados na prática de Atividades Assistidas por Animais (AAA) em hospitais sugerem que os assistidos demonstraram alegria na presença do cão e, como que distraídos pela interação com o animal, puderam minimizar desconfortos (ICHITANI, 2015). As postagens ainda transmitem espontaneidade e relaxamento dos pacientes em contato com o cão (PORTO; CASSOL, 2007). 
Nesse cenário, cabe ainda sublinhar que a presença do cão também impacta positivamente, não só apenas os assistidos, como também no comportamento dos profissionais envolvidos (MARCUS et al., 2012), nos cuidados dos pacientes hospitalizados.

No que diz respeito às atividades praticadas pelo paciente junto ao cão, grande parte das cenas apresentaram o contato físico entre ambos. Nessa direção, pesquisas confirmam que esse contato provoca efeitos hormonais importantes como estímulo da produção da endorfina (COLE; GAWLISKI, 2000), o que pode estar associado à sensação de bem-estar observada nas imagens. Os cães ainda emprestam ao conteúdo do feed uma sensação tranquila e amena (KÉRTÉSZ; BERZLEJA, 2019), o que pude constatar pela minha própria percepção durante a coleta e análise do material.

Sobre atividades desenvolvidas pelo par humano-cão, a Leitura teve apenas uma ocorrência em postagens nacionais e estudantes não apareceram; o que chama atenção ao referenciar Petenucci (2018) que afirma que a leitura se torna uma atividade mais prazerosa quando feita na companhia do cão. Nas postagens internacionais a atividade de leitura tem 4 ocorrências, todas no EUA. Assim, sugerese mais estudos sobre o tema.

A partir dessas considerações, revisitamos Bowlby (1990) por meio do Comportamento do Apego, no qual ocorre a aproximação entre indivíduos, onde um busca o amparo no outro por interpretá-lo como mais hábil a encarar e enfrentar situações.

Cabe ainda citar um repertório de atitudes básicas de apego (BOWLBY; AINSWORTH, 1969; 1985 APUD PIRES, 2017, p. 45) como "seguir, manter-se perto, tocar, sorrir, ter contato visual, aconchegar-se e agarrar-se ao outro" — evidentes nas imagens da amostra. Com base no referencial teórico, as cenas capturadas e publicadas na rede social demonstraram de forma clara o papel do cão no contexto específico o qual esta pesquisa se propôs observar. 


\section{CONCLUSÃO}

Esta pesquisa ofereceu dados significativos sobre a relação humano-cão no contexto da saúde humana obtidos por meio de postagens na rede social Instagram, em relação à localização geográfica de origem; características dos assistidos (tipo de fragilidade, sexo e faixa etária), local de atendimento; tipo de atividade realizada e áreas de conhecimento envolvidas.

Contudo, observa-se que é tênue a desejável articulação entre a produção científica sobre o tema e os conteúdos veiculados na rede social estudada. Tal constatação justifica a continuidade do presente estudo por meio da criação de uma plataforma digital que promova tal articulação, com a finalidade de reunir informações que possibilitem o diálogo com a comunidade científica, contribuam para a elaboração de políticas de saúde e estimulem o acesso de internautas às Intervenções Assistidas por Animais (IAA).

\section{REFERÊNCIAS}

ALBUQUERQUE, Natalia de Souza CIARI, Monica Baptista. Cães e seres humanos: uma relação forte, complexa, duradoura e vantajosa. In: CHELINI, Marie Odile Monier; OTTA, Emma. Terapia Assistida por Animais. Barueri, SP: Manole, Cap. 01, p. 01-22. 2016.

BOWLBY, John. Apego: a natureza do vínculo. 2. ed. São Paulo: Martins Fontes, 1990.

CGI.BR/NIC.BR. Centro Regional de Estudos para o Desenvolvimento da Sociedade da Informação (Cetic.br). Pesquisa sobre o Uso das Tecnologias de Informação e Comunicação nos domicílios brasileiros. TIC Domicílios, 2018. Disponível em: http://data.cetic.br/cetic/explore - [acesso em 15/abr/2019].

CHANDLER, Craig. Animal Assisted therapy in counseling. $2^{\mathrm{a}}$ ed. New York: Routledge, 2005. 
COELHO, Pietro Giuliboni Nemr. Fotos, Fachadas e Personas: A construção Identitária por Meio do Uso do Aplicativo Instagram. [dissertação]. São Paulo (SP): Escola Superior de Propaganda e Marketing. Programa de Pós-Graduação em Comunicação e Práticas de Consumo. 2016.

COLE, Kathie; GAWLINSKI, Anna. Animal-assisted therapy: the human-animal bond. AACN Clinical Issues. vol. 30, p. 529-537, 2000.

CRAMER, Theresa. Animal Influencers Around the Globe. EContent. vol. 41, n. 3, p. 9, 2018

D'ANGELO, Pedro. Pesquisa sobre o uso de Instagram no Brasil: hábitos, frequência e relação com as empresas. 2019. Disponível em: [https://blog.opinionbox.com/pesquisa-uso-de-instagram-no-brasil/] - [acesso em 8/dez/2019].

DOMINGUES, Camila Mantovani. Terapia Fonoaudiológica Assistida por Cães: Estudo de Casos Clínicos [dissertação]. São Paulo (SP): Pontifícia Universidade Católica de São Paulo. Programa de Estudos Pós-Graduados em Fonoaudiologia. 2007.

FARACO, Ceres Berger. Interação humano-cão: o social constituído pela relação interespécie [tese]. Porto Alegre (RS): Pontifícia Universidade Católica do Rio Grande do Sul. Doutorado em Psicologia. 2008.

FARACO, Ceres Berger; LANTZMAN, Mauro. Relação entre Humano e Animais de Companhia. In: FARACO, Ceres Berger; SOARES, Guilherme Marques. Fundamentos do Comportamento Canino e Felino. São Paulo: Ed Medvet. p. 1-12, 2013

FERREIRA, Leila Costa. O que aprendemos com a Web 2.0: novos rumos para a aprendizagem. In: SANTANA MOR, RAMOS MA, ALVES AB. (Orgs.) Actas do Encontro Internacional Discurso Metodologia e Tecnologia, Miranda do Douro: CEAMM. p. 237-247, 2007. 
FINE, Aubrey. Animals and therapists: incorporating animals in outpatient psychotherapy'. In: Handbook on Animal Assisted Therapy: Theoretical Foundations and Guidelines for Practice. San Diego: Academic Press. p.179-211, 2000.

FOGLE, Ben. Eyewitness Companions: Dogs. Londres (Reino Unido): Dorling Kindersley, 2006.

GALIBERT, Francis; QUIGNON, Pascale; HITTE, Christophe; ANDRÉ, Catherine. Toward understanding dog evolutionary and domestication history. Comptes Rendus Biologies. vol. 334, n. 3, p. 190-196, 2011.

GOMES, Adriana Albuquerque; MELCHIORI Lígia Ebner A teoria do apego na produção científica contemporânea. São Paulo: Ed Unesp; 2011.

GRANDGEORGE, Marine; HAUSBERGER, Martine. Human-animal relationships: from daily life to animal-assisted therapies. Istitute Super Sanità. vol. 47, n. 4, p. 397408, 2011.

HOOKER, Shirley; FREEMAN, Linda Holbrook; STEWART, Pamela. Pet therapy research: a historical review. Holist Nurs Pract. vol. 16, n. 5, p. 17-23, 2002.

ICHITANI, Tatiane. Efeito da Atividade Assistida por Animais na sensação de dor em crianças e adolescentes hospitalizados [dissertação] São Paulo (SP): Pontifícia Universidade Católica de São Paulo. Programa de Estudos Pós-Graduados em Fonoaudiologia. 2015.

ITU. International Telecommunication - ONU. 2018. Disponível em: https://www.itu.int/en/ITU-D/Statistics/Pages/default.aspx - [acesso em 20/fev/2020].

JEGATHEESAN, Brinda. The IAHAIO definitions for Animal Assisted Intervention - IAHAIO White Paper. USA. 2014. Disponível em: https://iahaio.org/wp/wpcontent/uploads/2017/05/iahaio-white-paper-final-nov-24-2014.pdf [acesso em 20/fev/2020]. 
KERTÉRSZ, Fanni; BERZLEJA, Zani. The furry side of Instagram: A study about dog influencers on Instagram. Master thesis, Media and Communication Studies Culture, Collaborative Media and Creative Industries. Suécia: Malmö University, 2019.

LEVINSON, Boris. Pet-oriented child psychotherapy. Springfield, IL: Charles C. Thomas, 1969.

LIMA, Marieli; SOUZA, Liliana A. Influência Positiva dos Animais de Ajuda Social. Interações: Sociedade e as novas modernidades. vol. 4, n. 6, 2004.

MACHADO, Jiliane de Abreu Campos; ROCHA, Jessé Ribeiro; SANTOS, Luana Maria. Terapia Assistida por Animais (TAA). Revista Científica Eletrônica de Medicina Veterinária. vol. VI, n. 10, 2008.

MARCUS, Dawn; BERNSTEIN, Cheryl; CONSTANTIN, Janet; KUNKEL, Frank; BREUER, Paula; HANLON, Raymond. Animal-Assisted Therapy at an outpatient pain management clinic. Pain Medicine. vol. 13, n. 1, p. 45-57, 2012.

MARTELETO, Regina Maria. Análise de redes sociais: aplicação nos estudos de transferência da informação. Ciência da Informação, Brasília. vol. 30, n. 1, p. 71-81, 2001.

NIGHTINGALE, Florence. Notes on Nursing. New York, NY: Dover Publications; 1969 [1860].

PETENUCCI, Aandrea Lorenzon. Efeitos da educação assistida por animais na leitura em um grupo de estudantes do Ensino Fundamental [dissertação]. São Paulo (SP): Pontifícia Universidade Católica de São Paulo. Programa de Estudos PósGraduados em Fonoaudiologia; 2018.

PINTO, Pedro; THEODORO, Ingrid; OLIVEIRA, Jonice. Comportamento das hashtags durante grandes eventos. In: Workshop sobre aspectos da interação humano-computador na web social (WAIHCWS), 7. 2016, São Paulo. Anais do VII 
Workshop sobre Aspectos da Interação Humano-Computador para a Web Social. Porto Alegre: Sociedade Brasileira de Computação, p. 35-42. ISSN 2596-0296. dec. 2017.

PIRES, Marcelo Silva Alves. As ciências desenvolvimentais e o desafio da complexidade epistemológica: uma análise da teoria do apego de Bowlby [tese]. Salvador (BA): Universidade Federal da Bahia. Programa de Pós-Graduação em Psicologia. Instituto de Psicologia. 2017.

PORTO, Rosane; CASSOL, Sabrina. Zooterapia uma Lição de Cidadania: O Cão Sociabilizador e a Criança Vítima de Violência Intrafamiliar. Revista Discurso Jurídico. vol. 3, n. 2, p. 46-74, 2007.

RUITENBECK, Hendric Marinus. Freud as We Knew Him. Detroit: Wayne State University Press. p. 379, 1973.

SALLES, Felipe. Apptuts. Disponível em: [https://www.apptuts.net/tutorial/redessociais/hashtags-mais-populares-no-instagram]. [acesso em 17/jan/2020].

SEGUIN, Elida; ARAÚJO, Luciane Martins; CORDEIRO, Miguel dos Reis. Uma Nova Família: a Multiespécie. Revista de Direito Ambiental. vol. 82, 2016.

SERPELL, James. In the Company of Animals. Cambridge: Cambridge University Pres. Diego: Academic Press, 1996

STATISTA. The Statistics Portal for Market Data. Hamburgo: Alemanha. Disponível em https://www.statista.com/topics/1882/instagram/.[acesso em 20/jan/2020]

TAVARES, Judy Lima. A Construção do persona Digital: Nova Identidade Assumida pelos Integrantes da Web 2.0 - UFAM. Amazonas, 2010.

THOMAS, Keith. $O$ homem e o mundo natural: mudanças de atitude em relação às plantas e aos animais (1500-1800). São Paulo: Companhia das Letras, 2001 [1983]. 
THOMPSON, John B. A Mídia e a modernidade: uma teoria social da mídia. Petrópolis: Ed. Vozes. 2011.

TOMAÉL, Maria Inês; ALCARÁ, Adriana Rosecler; DI CHIARA, Ivone Guerreiro. Das Redes Sociais à Inovação. Ciência da Informação. vol. 34, n. 2, p. 93-104, 2005.

WE ARE SOCIAL. Disponível em: https://datareportal.com/reports/digital-2019brazil?rq=brazil]. [acesso em 05/dez/2018].

\section{APÊNDICE - REFERÊNCIAS DE NOTA DE RODAPÉ}

1. HootSuite é um sistema norte-americano especializado em gestão de marcas na mídia social, fundado em 28 de novembro de 2008 por Ryan Holmes na cidade de Vancouver no Canadá

2. We Are Social é uma agência global que tem como foco solucionar problemas de marcas e negócios a partir do estudo do comportamento social nas redes.

3. Comportamento baseado na Teoria do Apego, que foi elaborada na segunda metade do século XX e se concentra na compreensão do vínculo afetivo entre uma criança e aquele que ocupa o papel de cuidador, normalmente a mãe (BOWLBY, 1990).

4. Associação global de organizações, com sede em Seattle - EUA, que se dedicam à prática, pesquisa e/ou educação em atividade assistida por animais, terapia assistida por animais e treinamento em animais de serviço. Essas atividades servem para promover a posse de animais de estimação, o vínculo humano-animal e abordagens respeitosas para o envolvimento com os animais.

5. O feed do Instagram é a página em que os usuários têm acesso às atualizações e postagens. Tudo que você posta poderá ser vistos pelos seus seguidores no feed do Insta deles e tudo que eles postam, você também pode conferir no seu feed. 
6. Neologismo com origem no termo self-portrait, que significa autorretrato, e é uma foto tirada e compartilhada na internet. Normalmente uma selfie é feita pela própria pessoa que aparece na foto, efeito esse que só é possível pela tecnologia do mobile que possui uma câmera incorporada e que permite essa possibilidade.

7. A Contato entende-se: cão no colo, carinho no cão, cão na cama junto com o assistido acamado, ou seja, o humano em contato com o animal com alguma parte do corpo.

Enviado: Julho, 2020.

Aprovado: Agosto, 2020. 